\title{
A Study of clinical profile, disease severity and treatment response of Movement disorders at a tertiary care teaching hospital
}

\author{
Pasha S.A. ${ }^{1}$, D. Phanibhushan ${ }^{2}$, T.V. Pavan Kumar ${ }^{3}$, B.Bhaskara Rao ${ }^{4}$, Pasha S.A. ${ }^{5}$ \\ ${ }^{1}$ Dr. Shaik Afsar Pasha, Associate Professor, Department of Neurology, ${ }^{2}$ Dr. D. Phanibhushan, Professor, ${ }^{3}$ Dr. T.V. \\ Pavan Kumar, Associate Professor, Department of Psychiatry, ${ }^{4}$ Dr. B. Bhaskara Rao, Professor, Department of General \\ Medicine, ${ }^{5}$ Dr. Shaik Arif Pasha, Professor, Department of Critical Care Medicine, 1-5-NRI Medical College and \\ General Hospital, Chinakakani, Mangalagiri, Guntur, Andhra Pradesh, India.
}

Corresponding Author: Dr. Shaik Afsar Pasha, Associate Professor, NRI Medical College and General Hospital, Chinakakani, Mangalagiri, Guntur, Andhra Pradesh, India. E-mail: afsarpasha81@gmail.com

\begin{abstract}
Background: Movement disorders are one of the common neurological problems seen by General physicians and neurophysicians. The clinical phenotype of Movement disorders is variable. Aim of the study: The objective of the study was to study the clinical profile, disease severity and treatment response of Movement disorders at a tertiary care teaching hospital. Results: The present study was a prospective observational study comprising 55 clinically detectable patients of movement disorders. Out of fifty-five, the frequency of various Movement disorders were as follows: Parkinson's disease- 25 (45.5\%), Wilson`s disease (WD)-9 (16.36\%), Progressivesupranuclear palsy- 8(14.54\%), Essential Tremor with Parkinson disease 5 (9.0\%), Choreiform disorders- 5(9.0\%). Mean MDS-UPDRS Part III score in OFF stage of PD was $57.7 \pm 13.2$ and in ON stage was $28.2 \pm 10.2$ suggesting significant improvement. Seventy-six percentages of PD patients had Good response to Dopaminergic agonists and Levodopa administration, while better response was seen in WD, ET+PD and the poor response in PSP patients respectively. Conclusion: Identifying and describing the clinical phenomenology of Movement disorders is the first step in the diagnostic evaluation of the patients as against to the localization in General Neurological disorders. Disease severity scales do assess the progression of the disease at the earliest and there are affordable regimes of various medications are available to treat them at the earliest, so as to reduce the morbidity and to increase health related quality of life.
\end{abstract}

Keywords: Movement disorders, PD, PSP, Disease severity scales, Levodopa

\section{Introduction}

Movement disorders (MD) are one of the common neurological diseases attending outpatient department. These patients do attend to different specialties based on the predominant system affliction. The clinical presentation of movement disorders is complex, often variable, and sometimes even bizarre. Establishing the correct diagnosis can, therefore, be difficult, even in the hands of experienced movement disorder specialists.

However, accurate recognition based onclinical acumen is important for several reasons [1]. The common Movement disorders are Parkinson's disease (PD), Essential tremor (ET), Drug induced parkinsonism (DIP), Chorieform disorders, ataxic syndromes, myoclonus and Parkinson's plus disorders. Using the

\footnotetext{
Manuscript received: $26^{\text {th }}$ December 2017

Reviewed: $4^{\text {th }}$ January 2018

Author Corrected: $11^{\text {th }}$ January 2018

Accepted for Publication: $17^{\text {th }}$ January 2018
}

different measures of quantitative scales can assess the disease severity. Many clinicians of the Indian nation rely on the western database for the recognition and management of Movement disorders, hence there were few hospital-based studies documenting the same. Hence, we considered to initiate this current study with an aim to study the clinical phenotype of Movement disorders, assessing the disease severity and the treatment response at a tertiary care teaching hospital in Andhra Pradesh, South India.

\section{Materials and Methods}

Patients suffering from movement disorders attending to neurology clinic of NRI Medical College and General hospital, Chinakakani, Guntur, Andhra Pradesh, India, were evaluated for the Clinical Phenotype and were diagnosed with predominantly recognizable movement 
disorder based on the defined clinical criteria.Using quantitative scales, assessed the disease severity. The patients were treated with different medication regimes based on the movement disorder. The study had cleared the institutional ethics committee requirements.

Study site: This study was conducted in the Department of Neurology in NRI Medical college and General hospital, which is a tertiary care teaching hospital located in Andhra Pradesh, India.

Stud population: The study population included all adult patients diagnosed as Movement disorders based on reliable history and clinical examination.

Sampling size and sampling method: A group of 55 eligible consenting participants satisfying the inclusion criteria were included in the study.

The study was a prospective, cross sectional, observational, hospital based study.

Study duration: The study was conducted over one year period from September 2015 to August 2016.

\section{Inclusion criteria}

1. Patients of any gender with age $>18$ years presenting with Movement disorders.

2. Both Primary and secondary Movement disorders mainly Metabolic and Vascular etiology

\section{Exclusion criteria}

1. Patients of age $<18$ years.

2. Drug induced Movement disorders and Posttraumatic Movement disorders

Statistical Methods- IBM SPSS statistical software version 21 was used for statistical analysis. Socio demographic variables like age and gender, education, occupation, socioeconomic status, etc were taken as explanatory parameters.

Descriptive analysis of all the explanatory and outcome parameters was done. All the categorical variables were presented in frequencies and percentages.

The numerical variables presented in Means and Standard deviations. Chi-square test was used to test the stastical significant association between the falls and executive dysfunction in PSP patients.

IBM SPSS statistical software version 21 was used for statistical analysis [2].

Study procedure-After obtaining informed consent, all patients underwent clinical examination and assessment of disease severity with applicable disease severity scales based on the predominant movement disorder like

i) MDS-UPDRS part III - Movement disorder societyunified Parkinson disease severity rating scale part 3,[3]

ii)Global assessment scale for Wilson disease (WD)[4]

iii) PSP Rating scale-Progressive supranuclear palsy rating scale [5] iv) FAB-Frontal lobe assessment battery [6] v) TETRAS- The essential tremor assessment scale [7] vi)UCRS- Unified chorea rating scale [8].

The patients medication response was graded as $\mathrm{G}$ for Good, B-Better and P for Poor response and these were defined as follows: G-Good - satisfying response of relief of motor symptoms as reported by patient and confirmed by the clinician at least for 4-6 hour after medication, B-Better - patient reports persistence of the motor symptoms while on medication but the clinical examination revealed better performance, P-Poor unsatisfactory response and no relief of symptoms and no change with medication and confirmed by clinician too.

\section{Results}

The present study was a prospective observational study comprising 55 clinically detectable patients of various movement disorders. Out of fifty five, the frequency of various Movement disorders were as follows:

Parkinson's disease - 25 (45.5\%), Wilson`s disease (WD)- 9 (16.36\%), Progressivesupranuclear palsy- 8(14.54\%), Essential Tremor with Parkinson disease $5(9.0 \%)$, Choreiform disorders- 5(9.0\%), Multiple system atrophy-cerebellar type- 1 (1.8\%), Spinocerebellar ataxia $-1(1.8 \%)$, NBIA $-1(1.8 \%)$.

The Mean age, age at onset and duration of movement disorders were 55.6 \pm 18.1 years, $52.8 \pm 17.9$ years and $2.8 \pm 1.07$ years respectively. 
Original Research Article

Table-1: Demographic characteristics of the patients.

\begin{tabular}{|c|c|c|c|c|c|c|}
\hline Variable & $\begin{array}{c}\text { Overall } \\
\mathbf{N = 5 5 *}\end{array}$ & $\begin{array}{c}\text { PD } \\
\mathbf{N = 2 5}\end{array}$ & $\begin{array}{c}\text { WD } \\
\mathbf{N = 9}\end{array}$ & $\begin{array}{c}\mathbf{E T + P D} \\
\mathbf{N = 5}\end{array}$ & $\begin{array}{c}\text { PSP } \\
\mathbf{N = 8}\end{array}$ & $\begin{array}{c}\text { Choreiform } \\
\text { disorders } \\
\mathbf{n = 5}\end{array}$ \\
\hline $\begin{array}{c}\text { Gender } \\
\text { Males } \\
\text { Females }\end{array}$ & 36 & 16 & 03 & 05 & 07 & 02 \\
\hline Mean age (years) & $55.6 \pm 18.1$ & $64.16 \pm 10.6$ & $24.8 \pm 5.4$ & $52.6 \pm 2.8$ & $69.12 \pm 8.6$ & $55.2 \pm 13.4$ \\
\hline $\begin{array}{c}\text { Mean age at onset } \\
\text { (Years) }\end{array}$ & $52.8 \pm 17.9$ & $61.28 \pm 10.4$ & $22.6 \pm 5.1$ & $48.4 \pm 3.8$ & $66.12 \pm 8.7$ & $53.4 \pm 14.8$ \\
\hline $\begin{array}{c}\text { Mean duration } \\
\text { (Years) }\end{array}$ & $2.8 \pm 1.07$ & $2.9 \pm 1.0$ & $2.2 \pm 0.8$ & $4.2 \pm 1.0$ & $3.0 \pm 0.8$ & $1.8 \pm 1.0$ \\
\hline Mean MMSE Scores & $24.8 \pm 2.2$ & $23.5 \pm 4.0$ & $26.2 \pm 3.2$ & $26.3 \pm 4.3$ & $19.2 \pm 2.2$ & $25.7 \pm 4.4$ \\
\hline
\end{tabular}

MMSE-Mini mental status examination, PD-Parkinson`s disease, WD-Wilsons disease, ET+PD- Essential tremor with PD, PSP-Progressive supranuclear palsy

*Note: single cases of each MSA-C, SCA-1 and NBIA haven 't included in the table.

Males outnumber the females in the overall, PD, ET+PD and PSP groups while it was the reverse in WD, Choreiform disorders. [Table 1]

The Mean age, age at onset and duration of movement disorders were $55.6 \pm 18.1$ years, $52.8 \pm 17.9$ years and $2.8 \pm 1.07$ years respectively. The frequency of Males and Females were 36 (65.45\%) and 19 (34.54) respectively. We found 3 different age groups of which patients were suffering from. WD patients were the younger in third decade while patients of ET+PD and choreiform disorders were in $5^{\text {th }}$ decade and patients of PD and PSP were in $7^{\text {th }}$ decade. Of the five patients of chorieform disorders, 2 patients were of Huntington's disease and 2 patients were Metabolic and one of Vascular etiology. Of the eight patients of PSP, 5 patients were PSP-RS (Richardson`s syndrome) and 3 were PSP-P (Parkinsonian variant of PSP). Mean MMSE scores were the least in PSP group while it was normal in other groups (Table 1).

Table-2: Clinical variables in various disease categories.

\begin{tabular}{|c|c|c|c|c|c|c|}
\hline Variable & $\begin{array}{c}\text { Overall } \\
\mathrm{N}=55 *(\%)\end{array}$ & $\begin{array}{c}\text { PD } \\
\mathrm{N}=25(\%)\end{array}$ & $\begin{array}{l}\text { WD } \\
\mathrm{N}=9\end{array}$ & $\begin{array}{c}\text { ET+PD } \\
\mathrm{N}=5\end{array}$ & $\begin{array}{l}\text { PSP } \\
\mathrm{N}=8\end{array}$ & $\begin{array}{c}\text { Choreifor } \\
\text { m disorder } \\
\mathbf{N}=\mathbf{5} \\
\end{array}$ \\
\hline Family history & $08(14.5)$ & $4(16)$ & 0 & $2(40)$ & 0 & $2(40 \%)$ \\
\hline $\begin{array}{c}\text { Tremor } \\
\text { Resting } \\
\text { Postural } \\
\text { Kinetic } \\
\text { Intentional } \\
\text { Re-emergent } \\
\text { Head } \\
\text { Voice } \\
\text { Chin tremor } \\
\end{array}$ & $\begin{array}{c}26(47.2) \\
14(25.4) \\
09(16.3) \\
07(12.7) \\
06 \\
05 \\
05 \\
08 \\
\end{array}$ & $\begin{array}{c}17(68) \\
04(16) \\
00 \\
00 \\
06 \\
00 \\
00 \\
08 \\
\end{array}$ & $\begin{array}{c}4(44.4) \\
5(55.5) \\
4(44.4) \\
3(33.3) \\
0 \\
5 \\
5 \\
0 \\
\end{array}$ & $\begin{array}{c}3(60) \\
5(100) \\
5(100) \\
4(80) \\
0 \\
5(100) \\
5(100) \\
0 \\
\end{array}$ & $\begin{array}{c}2(25) \\
0 \\
0 \\
0 \\
0 \\
0 \\
0 \\
0 \\
\end{array}$ & $\begin{array}{l}0 \\
0 \\
0 \\
0 \\
0 \\
0 \\
0 \\
0\end{array}$ \\
\hline $\begin{array}{c}\text { Dystonia } \\
\text { Hands } \\
\text { Legs } \\
\text { Trunk }\end{array}$ & $\begin{array}{c}29(52.7 \%) \\
13(23.6 \%) \\
11(20 \%)\end{array}$ & $\begin{array}{c}11(44 \%) \\
4(16 \%) \\
5(20 \%)\end{array}$ & $\begin{array}{l}7(77.7) \\
3(33.3) \\
1(11.1)\end{array}$ & $\begin{array}{c}3(60 \%) \\
0 \\
0\end{array}$ & $\begin{array}{c}6(75 \%) \\
4(50 \%) \\
3(37.5 \%)\end{array}$ & $\begin{array}{l}2(40 \%) \\
2(40 \%) \\
2(40 \%)\end{array}$ \\
\hline $\begin{array}{l}\text { Falls in history or } \\
\text { examination }\end{array}$ & $24(43.6 \%)$ & $10(40 \%)$ & $3(33.3)$ & $2(40 \%)$ & $8(100 \%)$ & $1(20 \%)$ \\
\hline Pyramidal signs & $5(09 \%)$ & 0 & 0 & 0 & $5(62.5 \%)$ & 0 \\
\hline Executive dysfunction & $17(30.9 \%)$ & $9(36 \%)$ & 0 & 0 & $8(100 \%)$ & 0 \\
\hline Diabetes & $3(5.4 \%)$ & 0 & 0 & 0 & 0 & $3(60 \%)$ \\
\hline Hypertension & $2(3.6 \%)$ & 0 & 0 & 0 & 0 & $2(40 \%)$ \\
\hline
\end{tabular}

In PSP group there was statistically significant association between the history of falls with p value of 0.001 (chi-square $\mathrm{x}^{2}=1.21$ ), while it wasn `t significant in PD group with $\mathrm{p}$ value of 0.62 (chi-square $\mathrm{x}^{2}=0.24$ ). 
Executive dysfunction was statistically significant in patients of PSP group with p value of 0.001 (chi-square $x^{2}=20.9$ ), while it wasn $`$ in PD group ( $p$ value of 0.456 , chisquare $x^{2}=0.55$ ). (Table 2).

We found the dystonia in the hands and feet followed by trunk in PD (44\%, 16\%, 20\% respectively), PSP group (75\%, $50 \%, 37.5 \%$ respectively) and in WD $(77 \%, 33.3 \%, 11.1 \%$ respectively). (Table 2$)$

PD-Parkinson's disease, WD-Wilsons disease, ET+PD- Essential tremor with PD, PSP-Progressive supranuclear palsy. *Note: single cases of each MSA-C, SCA-1 and NBIA haven`t not included in the table.

The disease severity scales were used in each disease category. MDS-UPDRS Part III Motor examination scale had demonstrated significant improvement of scores in PD and mild improvement in ET+PD patients. The patients of ET+PD were assessed separately with TETRAS (The essential tremor rating assessment scale) summing up to a score of 44 (ADL+Performance score) suggesting a significant severity. $\mathrm{H}$ and $\mathrm{Y}$ staging of PD was showed significant improvement in the staging on levodopa challenge test. Unique and specific scales were used to assess the disease severity in PSP (PSPRS-PSP Rating scale-38.8 \pm 7.9 ), GAS (Global assessment scale-12.66 \pm 8.0 ) in Wilson`s disease and UCRS (Unified Chorea rating scale-13.4 \pm 6.2 ) in Choreiform disorders suggesting marked disability (Table 3).

Table-3: Clinical severity scales in diagnostic categories.

\begin{tabular}{|c|c|c|c|c|c|}
\hline Variable & $\begin{array}{c}\text { PD } \\
\mathbf{N = 2 5}\end{array}$ & $\begin{array}{c}\text { WD } \\
\mathbf{N = 9}\end{array}$ & $\begin{array}{c}\text { ET+PD } \\
\mathbf{N = 5}\end{array}$ & $\begin{array}{c}\text { PSP } \\
\mathbf{N = \mathbf { 8 }}\end{array}$ & $\begin{array}{c}\text { Choreiform } \\
\text { disorder } \\
\text { N=5 }\end{array}$ \\
\hline MMSE & $23.5 \pm 4.0$ & $26.2 \pm 3.2$ & $26.3 \pm 4.3$ & $19.2 \pm 2.2$ & $25.7 \pm 4.4$ \\
\hline FAB & $15.6 \pm 4.2$ & $16.3 \pm 2.2$ & $14.3 \pm 3.3$ & $9.2 \pm 3.2$ & $15.5 \pm 2.6$ \\
\hline $\begin{array}{c}\text { Mean MDS-UPDRS Part III } \\
\text { OFF score }\end{array}$ & $57.7 \pm 13.2$ & NA & $46.2 \pm 10.8$ & NA & NA \\
\hline $\begin{array}{c}\text { Mean MDS-UPDRS Part III } \\
\text { ON score }\end{array}$ & $28.2 \pm 10.2$ & NA & $37.6 \pm 8.3$ & NA & NA \\
\hline $\begin{array}{c}\text { Mean H and Y Stage OFF } \\
\text { score }\end{array}$ & $2.2 \pm 0.7$ & NA & $2.7 \pm 1.2$ & NA & NA \\
\hline Mean H and Y stage ON score & $1.7 \pm 0.6$ & NA & $2.0 \pm 0.8$ & NA & NA \\
\hline $\begin{array}{c}\text { Tremor Severity scales } \\
\text { (TETRAS) }\end{array}$ & NA & NA & 22.8 & NA & NA \\
\hline GAS for WD & NA & $12.66 \pm 8.0$ & NA & NA & NA \\
\hline PSP-RS & NA & NA & NA & $38.8 \pm 7.9$ & NA \\
\hline Mean UCRS & NA & NA & NA & NA & $13.4 \pm 6.2$ \\
\hline
\end{tabular}

MMSE- Mini-Mental status examination, FAB- Frontal lobe assessment battery, MDS-UPDRS- Movement disorder society -Unified Parkinson disease rating scale part III, ON Stage: within 4-6 hours of levodopa or dopaminergic agonists, OFF stage: Atleast after 12 hours after ingestion of levodopa and dopaminergic agonists. H and Y- Hoehn and Yahr, TETRAS-The essential tremor rating assessment scale, GAS - Global assessment scale for Wilson's disease, UCRS- Unified chorea rating scale. NA- not applicable.

G-Good - satisfying response of relief of motor symptoms as reported by patient and confirmed by the clinician at least for 4-6 hour of medication, B-Better - patient reports persistence of the motor symptoms while on medication but the clinical examination revealed better performance, P-Poor - unsatisfactory response and no relief of symptoms and no change with medication and confirmed by clinicians too. NA - Not applicable.

The treatment response of these patients were variable that about $76 \%$ of PD patients had Good response to Dopaminergic agonists and Levodopa administration, while better response was seen in WD, ET+PD and poor response in PSP patients respectively. WD patients were treated with Zinc sulfate (Good response-100\%) and D-Penicillamine (Better response-55.5\%). Oral primidone in stepped up doses had shown good response in 100\% of ET+PD patients. Oral clonazepam had shown good response in $60 \%$ of acquired choreiform disorders but lesser in Huntington`s chorea (Table 4). 
Original Research Article

Table-4: Response to Drug therapy in various diagnostic categories.

\begin{tabular}{|c|c|c|c|c|c|}
\hline $\begin{array}{c}\text { Response to Drug therapy } \\
\text { (mg/day) }\end{array}$ & $\begin{array}{c}\text { PD } \\
\mathrm{N}=25(\%)\end{array}$ & $\begin{array}{c}\text { WD } \\
\mathrm{N}=9(\%)\end{array}$ & $\begin{array}{l}\text { ET+PD } \\
\mathrm{N}=5(\%)\end{array}$ & $\begin{array}{c}\text { PSP } \\
\mathrm{N}=8(\%)\end{array}$ & $\begin{array}{c}\text { Chorieform } \\
\mathbf{N}=5(\%)\end{array}$ \\
\hline Levodopa+Carbidopa- 375-400 & $\begin{array}{c}\text { G- } 19(76) \\
\text { B- } 6(24)\end{array}$ & B-4(44.4) & B-5(100) & $\begin{array}{l}\text { B-3(37.5) } \\
\text { P-5(62.5) }\end{array}$ & NA \\
\hline Rasageline-1.5-2 & $\begin{array}{l}\text { G- 19(76) } \\
\text { B-6(24) }\end{array}$ & B- 4(44.4) & B- $5(100)$ & B-3(37.5) & NA \\
\hline Ropinirole-1.5-2 & $\begin{array}{l}\text { G-19(76) } \\
\text { B-6(24) }\end{array}$ & B-4(44.4) & B- 5(100) & B-3(37.5) & NA \\
\hline Pramipexole-1.5-2 & $\begin{array}{l}\text { G-19(76) } \\
\text { B-6(24) }\end{array}$ & NA & B-5(100) & B-3(37.5) & NA \\
\hline Primidone-100-150 & NA & G-4(44.4) & B-5(100) & NA & NA \\
\hline Zinc sulphate-600 & NA & G-9(100) & NA & NA & NA \\
\hline D- Penicillamine-250 & NA & B-5(55.5) & NA & NA & NA \\
\hline Trihexyphenidyl-6-12 & $\begin{array}{l}\text { G-18(72) } \\
\text { B-7(28) }\end{array}$ & G-9(100) & B-5(100) & B-3(37.5) & NA \\
\hline Propanolol-40-80 & B-6(64) & G-9(100) & G-5(100) & NA & NA \\
\hline Clonazepam-0.5-1.0 & NA & B-9(100) & G-5(100) & NA & B-5(100) \\
\hline
\end{tabular}

\section{Discussion}

This is a prospective clinical observational study highlighting the clinical profile of various movement disorders with emphasis on assessment of disease severity and treatment response.

In our study, we found Parkinson`s disease being the most common Movement disorder. WD patients were the young and in third decade while patients of ET+PD and choreiform disorders were in $5^{\text {th }}$ decade and patients of PD and PSP were in $7^{\text {th }}$ decade. The executive dysfunction was most common in PSP group followed by PD group.

We found 25 PD patients of which 17 were of Tremor predominant and 8 cases were Akinetic Rigid type. The most common type of tremor was of 'resting tremor' in PD while Postural, kinetic and intentional tremor was seen in ET+PD cases[9-10].

In this group, we found five patients with ET+PD based on clinical overlap of the symptoms of tremor, which was bilateral, postural $(100 \%)$, kinetic $(100 \%)$ and as well as resting in 3 patients $(60 \%)$ along with significant body bradykinesia and postural instability. The unilateral resting tremor of PD increases in intensity while walking and it reduces in all ET patients, suggesting one to pay attention to resting tremor while patient is being seated or during walking. Kinetic tremor with intentional quality scores ET over PD. Reemergent tremor was seen only in 6 cases of PD (24\%). The findings of this study were in similar to that of Jankovic $\mathrm{J}$ et al,study characterizing re-emergent tremor of PD [11].

In our study we found $32 \%$ of PD patients were diagnosed by their severe brady kinesia, which was the most characteristic clinical hallmark manifested by asymmetrical slowness of activities of daily activities and was differentiated from senile slowness as it would be bilateral symmetrical. Micrographia was found in $64 \%$ of PD evidenced by progressive decrease in size of the written letters. The pathophysiology of bradykinesia results from failure of basal ganglia output to reinforce the cortical mechanisms that prepare and execute the commands to move [12].

Most common dystonia found was focal dystonia of hands and feet seen predominantly in PSP group followed by PD group. Striatal hand deformity characterized by ulnar deviation of hands, flexion of metacarpophalangeal joints, and extension of the interphalangeal joints, seen in $24 \%$ of PD patients.

Striatal toe characterized by extension of big toe was seen in $16 \%$ of PD patients while Winkler etal [13] had found in 13 of $62(21 \%)$ PD patients. 


\section{Original Research Article}

PSP group had significant cognitive decline with least MMSE scores. The Executive dysfunction may be related to dopaminergic fronto-subcortical deficits where as dementia may be associated with widespread cholinergic deficiency withatrophy in posterior parietal and temporal cortical regions of the brain [14-16]. WD and choreiform patients had normal cognition.

The scales of measurement further quantitated the severity and disability caused by each disease and helped in the management at least in PD as evidenced by improvement in scores in 'ON' stage, in response to levodopa challenge test. This study emphasizes one to utilize the scales in every disease so as to limit the disability and treat the disease.

Unfortunately, no effective neuroprotective treatment for PD is available today. Because most of the symptoms of $\mathrm{PD}$ are due to striatal dopamine deficiency, dopamine replacement therapyis the major medical approach in treating PD. The Most effective anti-parkinsonian agent is Levodopa [17] and is combined with carbidopa to prevent peripheral decarboxylation, gastrointestinal side effects and to increase cerebral levels. All our PD patients belong to mild to moderated stage of PD, independent for their activities.

Following the guidelines of the American Academy of Neurology, all our PD patients were started initially on Dopamine agonists (Young PD $<65$ years), followed by added on Levodopa in elderly PD ( $>65$ years), or when no efficacy found in former group [18-20].

Regarding the dose efficacy, the dose response relationship had been clearly demonstrated in RCTs, but the higher dose (600 $\mathrm{mg}$ per day) was associated with more motor complications, especially dyskinesia and the wearing off phenomena [21].

Motor fluctuations were found in less than $10 \%$ of our PD patients on Levodopa comprising peak dose dyskinesias, which were managed by reducing the dosage. Motor fluctuations may have different pathophysiological causes, but treatment strategies aiming at less pulsatile dopaminergic stimulation may be beneficial [22].

The use of smaller and more frequent doses of levodopa may help. If the patient is already using a MAO-B inhibitor when motor complications evolve, addition of a COMT inhibitor was recommended [23]. Amantadine treatment may be an alternative. The anti-dyskinetic effect of amantadine was well documented, and amantadine had been recommended against motor fluctuations and dyskinesias[24].

The Tremor of ET+PD was responsive to Propranolol, Primidone, Clonazepam and Levodopa. All our Wilson`s disease patients were on copper restricted diet and were started on Zinc sulfate in full doses 600 $\mathrm{mg} /$ day with gradual incremental doses of DPenicillamine $250 \mathrm{mg}$ (1/4 tab to start) for decoppering.

Successful decoppering can be monitored by an initial increase in urinary copper excretion, which subsequently falls, a reduction in the concentration of free copper in serum, and the fading of Kayser Fleischer rings. In our PSP group, we found the PSP-P group has significant improvement in motor symptoms with levodopa and partially dependent for ADL. However, patients PSP-R did not respond to any group of drugs.

\section{Conclusion}

Identifying and describing the clinical phenomenology of Movement disorders is the first step in the diagnostic evaluation of the patients as against to the localization in General Neurological disorders. Disease severity scales do assess the progression of the disease at the earliest and there are affordable regimes of various medications are available, to treat them at the earliest, so as to reduce the morbidity and to increase health related quality of life.

\section{What this study adds to existing knowledge?}

This hospital based descriptive study highlights the heterogenous sampling of the patients with various movement disorders based on the characteristic clinical phenotyping, ranging from hereditary to acquired disorders with disease specific assessment of the scales (qualitative and quantitative) and their treatment responses.

Utilizing the qualitative and quantitative respective scales for assessment of disease severity and their differing responses to varied drugs is a promising one out of this study.

\section{Contribution by each Author}

1. Research Project: A. Conception, B. Organization, C. Execution;

2. Statistical Analysis: A. Design, B. Execution, C.Review and Critique;

3. Manuscript: A. Writing of the first draft, B. Review and Critique. 


\section{Original Research Article}

Sk. Afsar P: 1A, 1B, 1C, 2A, 2B, 3A

DP: 1B, 1C, 2A, 2C, 3B

BBR.: 1C, 2B, 2C, 3B

Sk. Arif P: 1C, 2B, 2C, 3B

\section{Funding: Nil, Conflict of interest: None. Permission of IRB: Yes}

\section{References}

1. Abdo WF, van de Warrenburg BP, Burn DJ, Quinn $\mathrm{NP}$, Bloem BR. The clinicalapproach to movement disorders. Nat Rev Neurol. 2010 Jan; 6(1):29-37. doi: 10. 1038/nrneurol.2009.196.

2. Goetz CG, Tilley BC, Shaftman SR et al. Movement Disorder Society UPDRS Revision Task Force. Movement Disorder Society-sponsored revision of the Unified Parkinson's Disease Rating Scale (MDSUPDRS): scale presentation and clinimetric testing results. Mov Disord. 2008 Nov 15; 23(15):2129-70. doi: 10. $1002 /$ mds. 22340 .

3. Aggarwal A, Aggarwal N, Nagral A, Jankharia G, Bhatt M. A novel Global Assessment Scale for Wilson's Disease (GAS for WD). Mov Disord. 2009 Mar 15;24 (4): 509-18. doi: 10.1002/mds.22231.

4. Spss I. IBM SPSS statistics version 21. Boston, Mass: International Business Machines Corp. 2012: 126.

5. Golbe LI, Ohman-Strickland PA. A clinical rating scale for progressive supranuclear palsy. Brain. 2007 Jun; 130 (Pt 6):1552-65. Epub 2007 Apr 2.

6. Dubois B, Slachevsky A, Litvan I, Pillon B.The FAB: a Frontal Assessment Battery at bedside. Neurology. 2000 Dec 12; 55 (11):1621-6.DOI:https:// doi. org/10.1212/WNL.55.11.1621

7. Elble RJ. The Essential Tremor Rating Assessment Scale. J Neurol Neuromed (2016) 1(4): 34-38. DOI: 10.1002/mds.25162.

8. Antônio Lúcio Teixeira, Jr., Débora P. Maia, Francisco Cardoso.UFMG Sydenham's Chorea Rating Scale (USCRS): Reliability and Consistency Movement Disorders Vol. 20, No. 5, 2005, pp. 585-91. DOI: 10.1002/mds.20377.

9. Toth C, Rajput M, Rajput AH. Anomalies of asymmetry of clinical signs in parkinsonism. Mov Disord. 2004 Feb;19(2):151-7.
10. Bhidayasiri R. Differential diagnosis of common tremor syndromes. Postgrad Med J. 2005 Dec; 81 (962): 756-62.

11. Jankovic J, Schwartz KS, Ondo W. Re-emergent tremor of Parkinson's disease. J Neurol Neurosurg Psychiatry. 1999 Nov;67(5):646-50.

12. Jankovic J: Pathophysiology and clinical assessment of Parkinsonian symptoms and signs. In Pahwa R, Lyons K, Koller WC (ed): Handbook of Parkinsons disease. New York, Marcel Dekker,2003,pp71-107.

13. Winkler AS, Reuter I, Harwood G,Chaudhuri KR: The frequency and significance of striatal toe in Parkinsonism. Parkinsonism Relat Disord 2002;9:97101. PMID:12473399

14. Brooks DJ, Pavese N. Imaging non-motor aspects of Parkinson's disease. Prog Brain Res. 2010;184:205-18. doi: 10.1016/S0079-6123(10)84011-7.

15. Ibarretxe-Bilbao, N., Junque, C., Marti, M. And Tolosa, E. Brain structural MRI correlates of cognitive dysfunctions in Parkinson's disease. J NeurolSci 2011a 310: 70-74.DOI: 10.1016/j.jns.2011.07.054. Epub 2011 Aug 23.

16. Svenningsson P, Westman E, Ballard C, Aarsland D. Cognitive impairment in patients with Parkinson's disease: diagnosis, biomarkers, and treatment. Lancet Neurol. 2012 Aug;11(8):697-707. doi: 10.1016/S14744422 (12)70152-7.

17. Nutt JG, Wooten GF. Clinical practice. Diagnosis and initial management of Parkinson's disease. N Engl J Med. 2005 Sep 8;353(10):1021-7.

18. Ferreira JJ, Katzenschlager R, Bloem BR et al. Summary of the recommendations of the EFNS/MDSES review on therapeutic management of Parkinson's disease. Eur J Neurol. 2013 Jan; 20(1):5-15. doi: 10. 1111/j. 1468-1331.2012.03866.x.

19. Grimes D, Gordon J, Snelgrove Bet al. Canadian Nourological Sciences Federation. Canadian Guidelines on Parkinson's Disease. Can J Neurol Sci. 2012 Jul;39(4 Suppl 4):S1-30.

20. Miyasaki JM, Martin W, Suchowersky O, Weiner WJ, Lang AE. Practice parameter: initiation of treatment for Parkinson's disease: an evidence-based review: report of the Quality Standards Subcommittee 


\section{Original Research Article}

of the American Academy of Neurology. Neurology. 2002 Jan 8;58(1):11-7.

21. Fahn S. Levodopa in the treatment of Parkinson's disease. J Neural Transm Suppl.2006;(71):1-15.

22. Chaudhuri KR, Rizos A, Sethi KD. Motor and nonmotor complications in Parkinson's disease: an argument for continuous drug delivery? J Neural Transm (Vienna). 2013 Sep; 120(9):1305-20. doi: 10. 1007/ s00702-013-0981-5. Epub 2013 Mar 2.
23. Sawada H, Oeda T, Kuno S, et al. Amantadine for dyskinesias in Parkinson's disease: a randomized controlled trial. PLoS One. 2010;5(12):e15298.DOI: 10. 1371/journal.pone.0015298.

24. Ory-Magne F, Corvol JC, Azulay JPet al. NS-Park CIC Network. Withdrawing Amantadine in dyskinetic patients with Parkinson disease: the AMANDYSK trial. Neurology. 2014 Jan 28; 82(4): 300-7. doi: 10.1212/ WNL. 0000000000000050. Epub 2013 Dec 26.

\section{How to cite this article?}

Pasha S.A, D. Phanibhushan, T.V. Pavan Kumar, B. Bhaskara Rao, Pasha S.A. A Study of clinical profile, disease severity and treatment response of Movement disorders at a tertiary care teaching hospital. Int J Med Res Rev 2018;6(01):10-17. doi:10.17511/ijmrr. 2018.i01.03. 